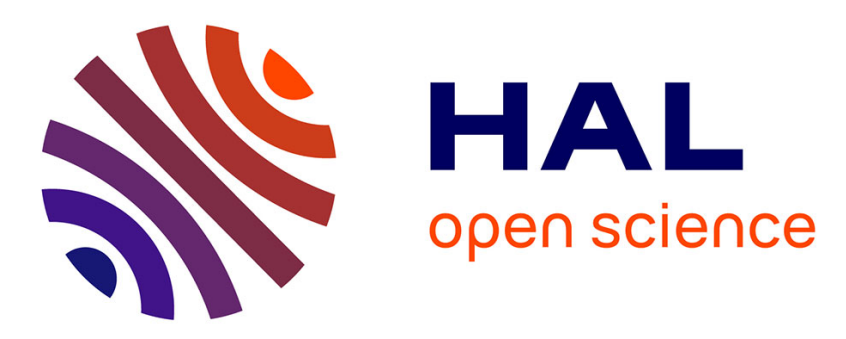

\title{
Job Protection, Housing Market Regulation and the Youth
}

\author{
Antoine Bonleu, Bruno Decreuse, Tanguy van Ypersele
}

\section{To cite this version:}

Antoine Bonleu, Bruno Decreuse, Tanguy van Ypersele. Job Protection, Housing Market Regulation and the Youth. Journal of Public Economic Theory, 2019, 21 (6), pp.1017-1036. 10.1111/jpet.12323 . halshs-02566548

\section{HAL Id: halshs-02566548 \\ https://shs.hal.science/halshs-02566548}

Submitted on 7 May 2020

HAL is a multi-disciplinary open access archive for the deposit and dissemination of scientific research documents, whether they are published or not. The documents may come from teaching and research institutions in France or abroad, or from public or private research centers.
L'archive ouverte pluridisciplinaire HAL, est destinée au dépôt et à la diffusion de documents scientifiques de niveau recherche, publiés ou non, émanant des établissements d'enseignement et de recherche français ou étrangers, des laboratoires publics ou privés. 


\title{
Job protection, housing market regulation, and the youth
}

\author{
Antoine Bonleu, Bruno Decreuse, Tanguy van Ypersele
}

Aix-Marseille Université, CNRS, EHESS, Centrale Marseille, AMSE, Marseille, France

\section{Correspondence}

Tanguy van Ypersele, AMSE, Chateau Lafarge, 13290 Les Milles, France.

Email: tanguy.vy@univ-amu.fr

Young Europeans experience high unemployment rates, job instability, and late emancipation. Meanwhile, they do not support reforms weakening protection on long-term contracts. In this paper, we suggest a possible rationale for such reform distaste. When the rental market is strongly regulated, landlords screen applicants with regard to their ability to pay the rent. Protecting regular jobs offers a second-best technology to sort workers, thereby increasing the rental market size. We provide a model where nonemployed workers demand protected jobs despite unemployment and the share of short-term jobs increases, whereas the individual risk of dismissal is unaffected. Our theory can be extended to alternative risks and markets involving correlated risks and commitment under imper-fect information.

\section{KEYWORDS}

labor market dualism, rent default, screening

\section{1 | INTRODUCTION}

Young Europeans struggle to find jobs, are over represented in temporary employment, and leave the parental home remarkably late. It is consensual to blame labor and housing market institutions as being responsible for these outcomes. Housing market regulation (HMR) has been accused of reducing the rental market size, thereby hampering worker mobility. Employment protection legislation (EPL) is viewed as detrimental to labor market entrants by depleting the supply of vacancies and closing access to long-term jobs. However, the youth support for labor market reforms is tenuous. Figure 1 shows that the preference for protected jobs does not vary much with age within countries. In France, youth have massively demonstrated against reforms of job protection in 2006 and 2016. 


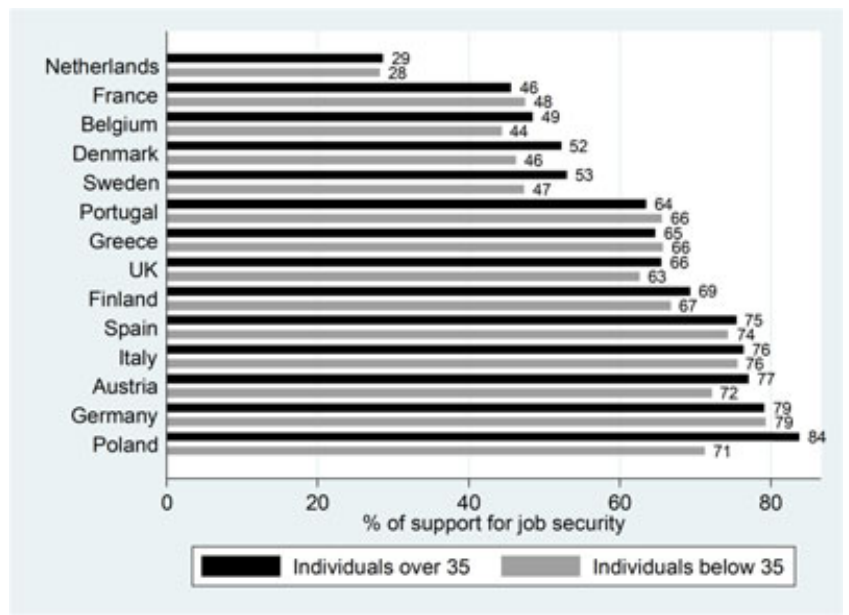

FIGURE 1 The demand for job security by age group in European countries, 1999-2001. Job security is derived from the third wave of the European Values Survey (1999-2001). It is the percentage of individuals who claim that it is important to have good job security. The variable is computed for two age groups, those between 16 and 35 and those who are older [Color figure can be viewed at wileyonlinelibrary.com]

Distrust vis-à-vis pro-market reforms may be rooted in the cultural or legal traits of continental European countries. ${ }^{1}$ In this paper, we argue that youth distaste for reforms of job protection is rational in a context where the rental market is strongly regulated. The key idea is as follows: HMR generates a social demand for job protection as a second-best technology to signal workers' ability to pay the rent. When the rental market is strongly regulated, landlords need to screen applicants on the basis of the expected risk of rent default. In this goal, landlords use labor market signals to figure out the individual risk of dismissal. When permanent jobs are not protected, selection in long-term employment is low and the mean risk of dismissal is large. Thus, landlords are reluctant to rent their dwellings. Protecting jobs forces firms to be more selective so that the quality of the signal conveyed by labor market contracts increases.

Our analysis is motivated by a series of aggregate correlations displayed by the panel of Figure 2a-d. We use two indices measuring the extent of EPL and HMR: the OECD strictness index of EPL on regular employment and the index of procedural formalism built by Djankov, LaPorta, Lopez-de-Silanes, and Shleifer (2003) and extended by Balas, LaPorta, Lopez-de-Silanes, and Shleifer (2009). They focus on the eviction of a tenant who does not pay the rent. The index is built from several subindices that describe the exact procedure used by litigants and courts. Youth employment and emancipation are measured from the European Community Household Panel (ECHP), which covers the period 19942001. The youth employment rate is the ratio of employees to total population of 16-35-year-olds, whereas the emancipation rate is the proportion of 16-35-year-olds who do not live with parents.

Figure 2a,b shows that young persons living in countries where the rental market is very regulated struggle to find jobs and quit the family home very late. Figure $2 c$ shows the proportion of young employees in a temporary job over total youth employment against the EPL index. Young workers are more likely to occupy short-term jobs in countries that strongly protect long-term jobs. Lastly, Figure $2 \mathrm{~d}$ highlights the positive correlation between the youth demand for job protection and HMR in OECD countries.

We provide a model of the housing and labor markets for young workers predicting these aggregate correlations at aggregate level. In this model, job protection reduces the odds of employment, increases the share

\footnotetext{
${ }^{1}$ Botero, Djankov, LaPorta, and Lopez-de-Silanes (2004) put forward the role of the legal origins of the judicial system, French origins being more prone to regulating markets. Algan and Cahuc (2006) highlight machismo and the dominant religion. Algan and Cahuc (2009) examine the role of civic attitudes. Alesina, Algan, Cahuc, and Giuliano (2015) focus on family values.
} 
(a)

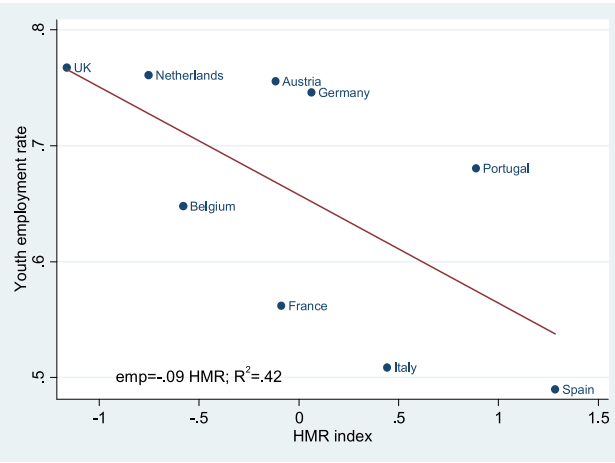

(c)

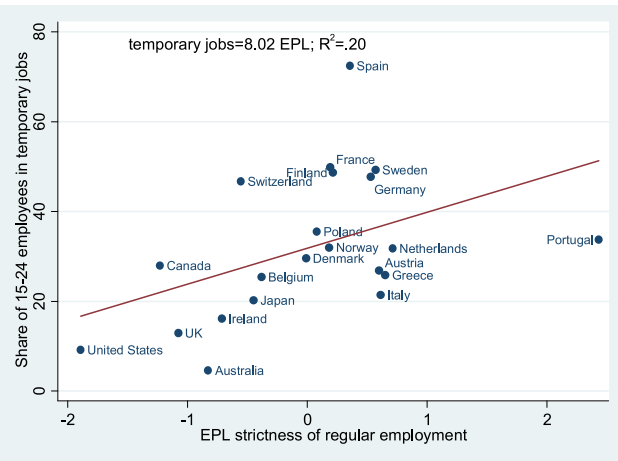

(b)

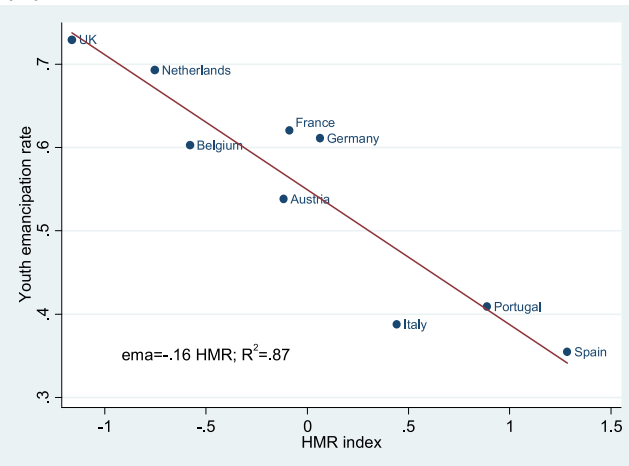

(d)

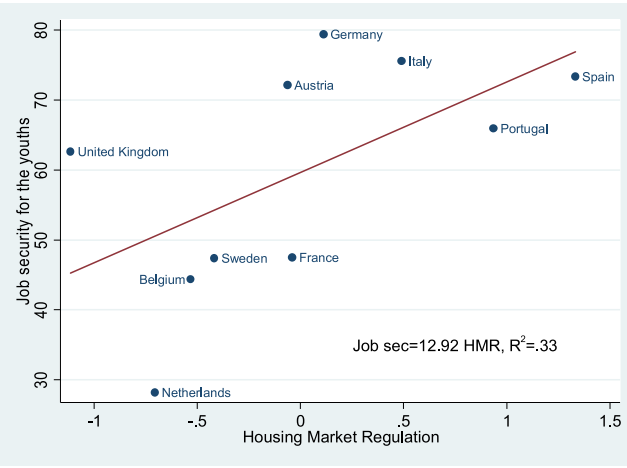

FIGURE 2 (a) Youth employment and HMR in Europe, 1994-2001. Youth employment is the ECHP ratio of employees to total population among 16-35-year-olds over the period 1994-2001. HMR is the degree of procedural formalism described by Balas et al. (2009). The variable has been averaged over 7 years and centered at its period mean. (b) Youth emancipation and HMR in Europe, 1994-2001. The youth emancipation rate is the ECHP 16-35 proportion who do not live with parents. HMR is the degree of procedural formalism described by Balas et al. (2009). The variable has been averaged over 7 years and centered at its period mean. (c) Share of young employees in temporary employment vs. EPL on regular jobs in OECD countries, 1994-2001. The share of young employees is computed from OECD data and averaged over 7 years. The EPL variable has been averaged over 7 years and centered at its period mean. (d) Youth demand for job security and HMR, 1999-2001. Job security is computed from the third wave of the European Values Survey (1999-2001). It is the percentage of 16-35-year-olds who claim that it is important to have good job security. HMR is the degree of procedural formalism described by Balas et al. (2009). The variable has been averaged over 7 years and centered at its period mean [Color figure can be viewed at wileyonlinelibrary.com]

of employees in short-term contracts, and does not affect the individual risk of dismissal. Still, nonemployed (young) workers can be in favor of job protection and the social demand for job protection increases with HMR.

Firms offer short-term and long-term contracts, whereas landlords select applicants. Firms and landlords are confronted with a similar problem: assessing the ability of applicants to perform the job tasks or pay the rent. However, employers play first. By offering a long-term job instead of a short-term one, firms provide a signal to landlords. The value of this signal increases with the protection of long-term contracts. In countries where the rental market is not very regulated, landlords do not screen applicants who can easily be evicted in case of rent default. It follows that the social demand for job protection is low. The opposite situation prevails in countries where the rental market is heavily regulated. There the social demand for EPL is large.

Using job protection as a screening technology is a second-best response to landlords' informational problem. The use of this technology makes sense because the risk of rent default is positively correlated with the risk of 
dismissal. There is evidence showing that households are more likely to default on the rent or on the mortgage reimbursement when unemployed (see, e.g., Deng, Quigley, VanOrder, \& Mac, 1996; Eichholtz, 1995; Gerardi, Herkenhoff, Ohanian, \& Willen, 2015; Nivière, 2006; Serrano-Diaz, 2005). Meanwhile, regular jobs last much longer on average than short-term jobs. In the case of youth, labor contracts are the only exploitable signals for landlords. For instance, there is no clean history of rent payments and a landlord cannot contact previous landlords to know the applicants better.

Alternative risks and market situations also contribute to explaining the demand for job protection as a demand for a screening technology. These risks must be correlated with the probability of being successful in an ongoing relationship. They must be uninsured or only partly insured. The market situations must involve a screening phase taking place after the labor contract has been attributed. In Section 4, we discuss such risks and markets, like the risk of damage to the dwelling due to the tenant's behavior or the risk of mortgage default for lenders. In each case, the strength of regulation in the secondary market motivates screening and the induced demand for protected jobs.

This paper calls for reforms of the housing market to reduce the social demand for EPL. Decreuse and van Ypersele (2011) make a complementary point. In their model, job protection reduces the individual risk of dismissal and individuals contract loans with lenders to buy housing units. The equilibrium price of loans decreases with job protection. Therefore, nonemployed persons are inclined to set the legislation above the threshold maximizing employment. Our paper shares the view that job security is highly valued when the housing market is regulated. However, the economic mechanism differs: here job protection does not reduce the chance of losing one's job; instead it reveals (part of) an individual risk. The labor market block of our model borrows from Cahuc, Charlot, and Malherbet (2016) and Pries and Rogerson (2005) where each match is associated to a specific risk of dissolution. Selection into labor contracts generates composition effects responsible for the decreasing relationship between job protection and job loss probability. In an extension of our model, we account for these two complementary views of job destruction and job protection. They strengthen each other and explain the fact that the demand for job protection increases with the HMR.

The paper is complementary to the literature on the links between the housing and labor markets. This literature makes the general claim that factors limiting worker mobility have side effects on employment. For instance, the Oswald hypothesis posits that unemployment increases with housing ownership because owners are less mobile than renters and cannot easily respond to income or employment shocks by moving to an alternative location. Closer to our paper, Rupert and Wasmer (2012) argue that labor market institutions such as EPL or unemployment compensation have strong effects on unemployment in countries where the rental market is very regulated. In our basic model, HMR does not directly affect employment but decreases it through its impact on the demand for job protection. In an extension, we focus on an extreme situation where taking a job always involves moving to a new dwelling. Despite firms taking into account the effect of the labor contract on the rental probability, selection into employment is too low. Protecting LT jobs make firms more selective, which may improve employment and emancipation.

The paper relates to the literature on the positive analysis of job protection. In their analysis of the regulation of labor, Botero et al. (2004) distinguish market failure correction and rent-seeking arguments. In papers belonging to the former strand of arguments, the optimal level of protection depends on the nature of labor market distortions (see Blanchard \& Tirole, 2008, for a complete discussion involving EPL and unemployment insurance). In our approach, job protection is used to correct a lemon issue in the housing market. Fixing this problem destroys jobs, but the level of job protection improves access to rentals.

According to the rent-seeking argument, job protection benefits the majority of insiders who already hold regular jobs and is detrimental to outsiders (see, e.g., Saint-Paul, 2001). This literature makes important points but does not predict the wide support for job protection that goes well above the set of installed workers. ${ }^{2}$ Our model

${ }^{2}$ In Bonleu (Forthcoming), the rental market regulation is a barrier to entry for would-be renters who are not embedded in local social networks. By analogy, job protection could benefit nonemployed workers who personally know some of the employers or their employees (see, e.g., Stupnytska \& Zaharieva, 2017, for a search model with social contacts). 
abstracts from such insiders because already established workers who have found a dwelling do not derive additional benefits from job protection. In an extension of our model, we show job protection is supported by a coalition of individuals with a large probability of success and individuals with a low probability of success. The former want to belong to a small elite club with large access to the housing market, whereas the latter want to be accompanied in short-term contracts by as many workers as possible to avoid stigmatization.

Lastly, our paper borrows from the literature on consumption commitments. Postlewaite, Samuelson, and Silverman (2008) argue that such consumption commitments induce endogenous risk aversion. Workers are willing to sign labor contracts involving an unemployment stage in exchange for lower prices for consumption goods. Similarly, in our approach workers ask for job security to improve their access to rentals. HMR generates a form of risk aversion that is specific to employed workers, thereby explaining why nonemployed workers support job protection. Section 2 presents the basic model where job protection is a second-best technology transmitting labor market signals to landlords facing a lemon problem. Section 3 derives optimal job protection. The signaling value of job protection increases with the rental market regulation, which explains why the society has strong preference for job protection despite its side effects on ST employment and overall youth employment. Section 4 discusses several extensions. Section 5 concludes.

\section{BASIC MODEL}

We develop a model of the labor and housing markets for young workers. This model features a social demand for job protection based on the extent of procedural formalism affecting judicial disputes in the rental market.

We consider a static economy peopled by identical individuals who all start unemployed and living with their parents. The model has two blocks. In the labor market block, workers and firms meet and the worker-firm pair receives an initial signal on the match quality. The worker is then hired in a short-term or long-term contract based on this signal and on the stringency of EPL. In the housing market, landlords observe workers' contracts and screen them on the basis of expected job security. Then, the match quality is revealed and the worker stays in the job or goes back to unemployment. In case of job loss, tenants default on the rent and landlords incur a loss due to the length of litigation and eviction procedures. The magnitude of the loss is exogenous and measures the degree of HMR.

We first specify the model agenda and then successively present the labor market and rental market blocks. Lastly, we discuss the comparative statics properties of equilibrium.

\subsection{Timing}

In the first stage, individuals search for jobs and firms choose whether they offer a long-term contract (LT) or a short-term one (ST). In the second stage, employed workers search for dwellings and landlords screen them according to their contract type. In the last stage, match quality is revealed and bad jobs are destroyed. Only the workers who stay employed pay the rent and enjoy housing consumption.

Wages and rents are exogenous. The exogenous-rent assumption is innocuous. In Appendix B, we illustrate this claim with a specific model of rent setting. The exogenous-wage assumption is more controversial, because the wage may partly reveal match quality. We postpone this discussion to Section 4 where we present several extensions. Hereafter, $w$ is the wage and the rent $r$ is normalized to one. We suppose that $w>r=1$. $^{3}$

\footnotetext{
${ }^{3}$ Price exogeneity abstracts from second-order effects of job protection on prices, so that the social demand for EPL cannot be attributed to such disputable effects. For instance, Leonardi and Pica (2013) exploit the 1990 Italian reform that introduced unjust dismissal costs for firms below 15 employees. They find that the slight average wage reduction induced by the reform hides highly heterogeneous effects. In a similar spirit, Casas-Arce and Saiz (2010) argue that procedural formalism in the rental market has heterogeneous effects on rents by redistributing income from movers to stayers.
} 


\section{2 | Labor market}

There is a continuum of firms. Each firm corresponds to a single job slot, which can be active or inactive. Turning active $\operatorname{costs} c>0$. Vacant jobs and unemployed workers meet according to a matching technology. Let $\theta$ be the ratio of vacant jobs to unemployed workers. The probability of meeting a firm is $m(\theta)$, whereas the probability of contacting a worker is $m(\theta) / \theta$, with $m(0)=0, m(\infty)=1, m^{\prime}>0, m^{\prime \prime}<0$, and $m^{\prime}(0)=1$. Strict concavity implies that $m(\theta) / \theta$ is strictly decreasing, while the Inada-type condition ensures that $\lim _{\theta \rightarrow 0} m(\theta) / \theta=1$ by L'Hôpital's rule.

Right after meeting, the firm-worker pair receives a signal on match quality. This signal consists in the objective probability, $p$, that the match is good. It consists of (i.i.d.) realizations of a random variable $P$ that is distributed according to the cumulative distribution function $F$ on $[0,1]$, that is, $\operatorname{Pr}(P \leq p)=F(p)$. The function $F$ has a continuous density $f \equiv F^{\prime}$. Firms make two decisions: whether to hire the worker or not, and, conditional on hiring, which contract they offer. Contracts are indexed by $i=S T$, LT and differ in two ways: on the one hand, they are associated to different costs of dismissal. The firing cost $t_{i} \geq 0$ is a pure loss to the pair and $t_{L T}=t \geq t_{S T}=0$. On the other hand, contracts differ in training opportunity: only the workers hired in a LT contract can receive training. Workers in a bad match are dismissed in all circumstances, while workers in a good match produce $y_{L}>w$ when untrained and $y_{H}>y_{L}$ when trained. The parameter $y_{H}$ measures output net of the training cost. We denote $\Delta y \equiv y_{H}-y_{L}$ the output differential between good and bad matches.

The trade-off is the following: a LT contract is more costly than a ST contract because the firm has to pay a cost in case of separation. However, offering a LT contract is advantageous because trained workers can be more productive. This advantage can be exploited when the match is good. Thus, the value of offering a LT contract increases with the signal on match quality.

The main purpose of the assumption whereby LT jobs are more productive than ST ones is to ensure that firms have incentive to offer LT jobs. Note, however, that workers in temporary jobs are less likely to receive training (see, e.g., Booth, Francesconi, \& Frank, 2002). More generally costly commitment favors match-specific investments, which this assumption broadly captures.

Let $\pi_{\mathrm{LT}}(p)$ and $\pi_{\mathrm{ST}}(p)$ denote, respectively, the profits associated with a LT contract and a ST one. We have

$$
\begin{gathered}
\pi_{L T}(p)=p\left(y_{H}-w\right)+(1-p)(0-t), \\
\pi_{S T}(p)=p\left(y_{L}-w\right) .
\end{gathered}
$$

The worker obtains a LT contract when

$$
p \geq p_{\mathrm{LT}}=\frac{t}{\Delta y+t}
$$

and a ST contract when

$$
p_{\mathrm{LT}}>p \geq 0
$$

The number of active jobs responds to a free-entry condition. This implies that

$$
c=\frac{m\left(\theta^{*}\right)}{\theta^{*}} \int_{0}^{1} \max \left\{\pi_{\mathrm{LT}}(p), \pi_{\mathrm{ST}}(p), 0\right\} d F(p) .
$$

Accounting for $p_{\mathrm{LT}}$, we have

$$
\begin{aligned}
c & =\frac{m\left(\theta^{*}\right)}{\theta^{*}}\left\{\int_{0}^{p_{L T}} \pi_{\mathrm{ST}}(p) d F(p)+\int_{P_{L T}}^{1} \pi_{\mathrm{LT}}(p) d F(p)\right\} \\
& =\frac{m\left(\theta^{*}\right)}{\theta^{*}}\left\{\int_{p_{L T}}^{1}(\Delta y+t)\left(p-p_{\mathrm{LT}}\right) d F(p)+\left(y_{\mathrm{L}}-w\right) \mathbb{E}(P)\right\} .
\end{aligned}
$$




\section{3 | Rental market}

Once they have a job offer, which happens with probability $m\left(\theta^{*}\right)$, all workers search for a dwelling. Each worker meets a single landlord. As the rent is normalized to one, the expected income derived from renting to a type-i tenant is $\left(1-\delta_{i}\right)+(1-\alpha) \delta_{i}=1-\alpha \delta_{i}$, where $\delta_{i}$ is the expected default probability and $1-\alpha \in[0,1]$ is the value of the dwelling with a defaulting tenant. Parameter $\alpha$ is a measure of HMR. Procedural formalism weakens property rights and landlords cannot recoup the full value of the dwelling in case of rent default. When $\alpha=0$, the expected income of the landlord is equal to one and does not depend on the default probability.

Landlords cannot observe the probability $p$ of being successful in employment. They use the employment contract to screen applicants. The contract type reveals the average match quality, $\mathbb{E}\left[P \mid P>p_{\mathrm{LT}}\right]$ for $L T$ contracts and $\mathbb{E}\left[P \mid P \leq p_{\mathrm{LT}}\right]$ for $\mathrm{ST}$ contracts. The corresponding default probabilities $\delta_{\mathrm{LT}}$ and $\delta_{\mathrm{ST}}$ are

$$
\delta_{\mathrm{LT}}=1-\frac{\int_{p_{\mathrm{LT}}}^{1} p f(p) d p}{1-F\left(p_{\mathrm{LT}}\right)} \text { with } \frac{d \delta_{\mathrm{LT}}}{d p_{\mathrm{LT}}}=-\frac{f\left(p_{\mathrm{LT}}\right)}{1-F\left(p_{\mathrm{LT}}\right)}\left(1-p_{\mathrm{LT}}-\delta_{\mathrm{LT}}\right)<0
$$

and

$$
\delta_{\mathrm{ST}}=1-\frac{\int_{0}^{p_{\mathrm{LT}}} p f(p) d p}{F\left(p_{\mathrm{LT}}\right)} \text { with } \frac{d \delta_{\mathrm{ST}}}{d p_{\mathrm{LT}}}=\frac{f\left(p_{\mathrm{LT}}\right)}{F\left(p_{\mathrm{LT}}\right)}\left(1-\delta_{\mathrm{ST}}-p_{\mathrm{LT}}\right)<0 .
$$

We have $\delta_{\mathrm{LT}}<1-P_{\mathrm{LT}}<\delta_{\mathrm{ST}}$. Landlords expect that workers in ST jobs are more likely to be dismissed, thereby defaulting on the rent. Importantly, the reason is not that LT contracts protect workers against the risk of dismissal. Instead, the contract type reveals the match-specific risk of dissolution. Moreover, the two default probabilities decrease with the threshold $p_{\mathrm{LT}}$. An increase in $p_{\mathrm{LT}}$ improves the mean probability of success in both groups: the marginal workers with the lowest $p$ in the group of LT workers become those with the highest $p$ in the group of ST workers.

Each landlord has an opportunity cost of renting $k$, which is distributed according to the cumulative distribution function (cdf) $H$. Landlords compare this opportunity cost to the expected income derived from renting $1-\alpha \delta_{i} \in[1-\alpha(1-\mathbb{E}(P)), 1]$. We suppose that the support of the $\operatorname{cdf} H$ is $[\mathbb{E}(P), 1]$ with no mass point. As we shall see, this restriction implies that the rental market collapses when all workers are hired in a LT contract and the rental market regulation is set at its maximum, that is, $\alpha=1$. Moreover, the function $H$ has a continuous and strictly positive density $h \equiv H^{\prime}$.

Workers with a LT contract are more likely to find a dwelling than workers with a ST contract. We have $\mu_{i}=H\left(1-\alpha \delta_{i}\right), i=\mathrm{ST}, \mathrm{LT}$. The probability $\mu_{i}$ decreases with the parameter of regulation, $\alpha$, and the default probability, $\delta_{i}$. As $\delta_{\mathrm{LT}}<\delta_{\mathrm{ST}}$, we have $\mu_{\mathrm{LT}}>\mu_{\mathrm{ST}}$ when $\alpha>0$.

\section{4 | Comparative statics}

We now discuss the impacts of the different regulation parameters on model outcomes. Let $e_{\mathrm{LT}}=m\left(\theta^{*}\right) \operatorname{Pr}\left(P \geq p_{\mathrm{LT}}\right) \mathbb{E}\left(P \mid P \geq p_{\mathrm{LT}}\right)$ be $\mathrm{LT}$ employment, $e_{\mathrm{ST}}=m\left(\theta^{*}\right) \operatorname{Pr}\left(P<p_{\mathrm{LT}}\right) \mathbb{E}\left(P \mid P<p_{\mathrm{LT}}\right)$ be ST employment and $e=e_{\mathrm{ST}}+e_{\mathrm{LT}}=m\left(\theta^{*}\right) \mathbb{E}(P)$ be overall employment. By construction, the fraction of emancipated workers is $q=e_{\mathrm{ST}} \mu_{\mathrm{ST}}+e_{\mathrm{LT}} \mu_{\mathrm{LT}}$.

The meeting probability $m\left(\theta^{*}\right)$ decreases with the cost of dismissal, whereas the probability $p_{\mathrm{LT}}$ of hiring a worker in a ST contract increases with it. An increase in $t$ is an increase in expected labor costs and firms create fewer vacancies as a result. Meanwhile, we have

$$
\frac{d p_{\mathrm{LT}}}{d t}=\frac{\Delta y}{(\Delta y+t)^{2}}>0
$$

When $t$ increases, firms substitute ST jobs to LT ones. Therefore, the threshold $p_{\mathrm{LT}}$ goes up. 
It follows that $d e_{\mathrm{LT}} / d t<0$ and $d e / d t<0$, whereas $d e_{\mathrm{ST}} / d t$ has an ambiguous sign. LT employment necessarily decreases because the contact probability $m\left(\theta^{*}\right)$ goes down and firms become less willing to offer LT contracts. The impact on ST employment is less clear-cut because firms have stronger incentive to hire workers in ST contracts. Lastly, overall employment $e=m\left(\theta^{*}\right) \mathbb{E}(P \mid)$ decreases with $t$.

As for the emancipation probability $q$, we have

$$
q=m\left(\theta^{*}\right)\left[\left(1-F\left(p_{\mathrm{LT}}\right)\right)\left(1-\delta_{\mathrm{LT}}\right) \mu_{\mathrm{LT}}+F\left(p_{\mathrm{LT}}\right)\left(1-\delta_{\mathrm{ST}}\right) \mu_{\mathrm{ST}}\right]
$$

Emancipation results from the conjunction of three events: finding a long-term job, with probability $m\left(\theta^{*}\right)\left(1-F\left(p_{\mathrm{LT}}\right)\right)$, or a short-term job, $m\left(\theta^{*}\right) F\left(p_{\mathrm{LT}}\right)$, keeping the job, $1-\delta_{i}$, and finding a rental, $\mu_{i}$. HMR has a negative impact on emancipation. The regulation parameter $\alpha$ reduces landlords' probability of accepting potential tenants. Therefore, both probabilities $\mu_{\mathrm{LT}}$ and $\mu_{\mathrm{ST}}$ decrease.

\section{3 | THE DEMAND FOR JOB PROTECTION}

We now argue nonemployed workers may have positive demand for protected jobs even though employment and the share of ST jobs increase with the cost of dismissal $t$. We consider a case where these workers actually want to leave the family home. Therefore, our arguments do not involve intra-family redistribution. ${ }^{4}$ In this goal, we suppose that consumption and emancipation are complementary goods in the utility function, which means that consumption is valued only when the person is emancipated.

The cost of dismissal that maximizes the expected utility of a typical worker before the signal $P$ is known, that is, under the veil of ignorance, is defined as follows:

$$
t^{*} \in \arg \max _{t \geq 0}\{q(w-1)=e(t) \bar{\mu}(t, \alpha)(w-1)\}
$$

with $\bar{\mu}(t, \alpha)=\left[\left(1-F\left(p_{\mathrm{LT}}\right)\right)\left(1-\delta_{\mathrm{LT}}\right) \mu_{\mathrm{LT}}+F\left(p_{\mathrm{LT}}\right)\left(1-\delta_{\mathrm{ST}}\right) \mu_{\mathrm{ST}}\right] / \mathbb{E}(P)$. As $w-1$ does not depend on $t$, solving $(10)$ is equivalent to maximizing the emancipation probability. ${ }^{5}$

Proposition 1 Let $t^{*} \equiv t^{*}(\alpha)$. There exists $\tilde{\alpha} \in(0,1)$ such that

(i) $t^{*}(0)=0$;

(ii) for all $\alpha>\tilde{\alpha}, t^{*}(\alpha)>0$ and solves

$$
\frac{t^{*} \bar{\mu}_{t}\left(t^{*}, \alpha\right)}{\bar{\mu}\left(t^{*}, \alpha\right)}=-\frac{t^{*} e^{\prime}\left(t^{*}\right)}{e\left(t^{*}\right)}>0,
$$

(iii) when $H$ is uniform, $d t^{*}(\alpha) / d \alpha>0$.

Proof Part (a) is proved below. The proofs of (b) and (c) are in Appendix A.

\footnotetext{
${ }^{4}$ Accounting for family help can affect the demand for insurance. See, for example, De Donder and Pestieau (2017) in the context of long-term care. ${ }^{5}$ In the more general case, the expected utility would be of the form $x(w)+e(t) \bar{\mu}(t, \alpha)[v(w-1)-x(w)]$, where $x$ is the utility when staying in the family home and $v$ is the utility when emancipated. Having $v$ linear is an innocuous assumption. Having $x(w)=0$ implies that there is always positive demand for job protection when $\alpha=1$, which simplifies the discussion.
} 
Part (i) states that there is no demand for employment protection in the absence of rental market regulation. Employment strictly decreases with $t$. Thus, $t=0$ is the employment-maximizer level of job protection, $e_{\max }$ is the corresponding employment level, and the emancipation probability is $q=e_{\mathrm{ST}} \mu_{\mathrm{ST}}+e_{\mathrm{LT}}\left(\mu_{\mathrm{LT}}-\mu_{\mathrm{ST}}\right)$. When $\alpha=0$, landlords do not pay attention to the labor contract and $\mu_{\mathrm{LT}}=\mu_{\mathrm{ST}}=H(1)=1$. Maximizing the emancipation probability is then equivalent to maximizing employment, which implies $t^{*}=0$.

Part (ii) shows that people need stable jobs when the rental market is strongly regulated. When $\alpha>0$, landlords lose part of the dwelling's value in case of default. Suppose $t=0$, then all workers are hired in a LT contract. It follows that the emancipation probability is $q=e_{\max } H(1-\alpha(1-\mathbb{E}(P)))$. As $\alpha$ increases, the probability of being accepted by the landlord goes down, reaching $H(\mathbb{E}(P))=0$ when $\alpha=1$. Therefore, setting $t^{*}>0$ is optimal when $\alpha=1$. This implies $\delta_{L T}<\mathbb{E}(P)$ and some of the landlords are willing to rent to workers in $L T$ contracts. Meanwhile, workers in ST contracts have to co-reside with parents. By continuity, $t^{*}>0$ when $\alpha$ is sufficiently large.

Part (ii) also shows the first-order condition of the maximization problem. The left-hand side is the elasticity of the landlords' average probability of accepting tenants. The right-hand side is the absolute value of the elasticity of employment. The cost of dismissal is set so that the probability gain in rental access balances the probability loss in employment.

The left-hand side of this condition involves three effects:

$$
\begin{aligned}
\mathbb{E}(P) \bar{\mu}_{t}\left(t^{*}, \alpha\right)= & \underbrace{-p_{\mathrm{LT}} f\left(p_{\mathrm{LT}}\right) \frac{d p_{\mathrm{LT}}}{d t}\left(\mu_{\mathrm{LT}}-\mu_{\mathrm{ST}}\right)}_{A<0}+\underbrace{\int_{p_{L T}}^{1} p d F(p) \frac{d H\left(1-\alpha \delta_{L T}\right)}{d t}}_{B>0} \\
& +\underbrace{\int_{0}^{p L T} p d F(p) \frac{d H\left(1-\alpha \delta_{S T}\right)}{d t}}_{C>0} .
\end{aligned}
$$

A marginal increase in the cost of dismissal reduces the pool of LT workers who benefit from a better access to rentals, thereby reducing the average probability of obtaining a lease $(A)$. However, this also raises the probability of obtaining a rental for both ST and LT workers $(B$ and $C)$. This phenomenon is due to composition effects in both groups. The marginal workers who quit the group of LT workers have the lowest probability of success in this group, but the largest one in the group of ST workers. Therefore, the mean expected risk of default decreases in both groups. These composition effects explain why protecting jobs may be interesting for nonemployed workers despite the negative impact of job protection on employment opportunities. The magnitude of the negative effect can be made as small as wanted by setting a sufficiently low $t$. This explains why the first-order condition can have a solution.

Part (iii) strengthens the main message of part (ii), that is, HMR tends to foster the social demand for job protection. We show the result when the cdf of landlords' opportunity costs is uniform. The value of screening increases with the regulation parameter $\alpha$. In heavily regulated rental markets, young workers are in favor of legislation that reduces the supply of vacancies, increases unemployment, and raises the proportion of ST employment even though the legislation does not affect the individual risk of job loss. The reason is that HMR creates a need for a technology helping landlords to screen heterogeneous applicants on the basis of their ability to pay the rent.

To conclude, the model equilibrium can replicate the nexus of aggregate facts shown in the Introduction. In particular, emancipation and employment are negatively correlated with HMR as in Figure 2a,b, the proportion of ST jobs increases with job protection as in Figure $2 c$, and HMR and the demand for job protection are positively correlated as in Figure 2d.

\section{4 | DISCUSSION}

In our model, job protection is a signaling device to transmit labor market signals to landlords. Its function is to improve the working of the rental market in the context of heavy rental regulation and rational landlords. 
In this section, we question a little further the validity of this statement. First, we argue that the support for job protection comes from alternative stakeholders in the society, for example, landlords, and alternative housing market risks, for example, mortgage default. Second, we extend the basic model in three directions: the wage may also signal the risk of job loss, job protection may directly affect this risk, and HMR may directly increase unemployment through reduced worker mobility. Lastly, we revisit the insider-outsider theory of job protection.

\section{1 | Other stakeholders}

Our model predicts that nonemployed people support job protection when the housing market is very regulated. We now argue that the support for job protection goes beyond youth and also comes from landlords.

Consider landlords with rental opportunity cost $k$. They expect to receive this opportunity cost $k$ plus the net rental gain $1-\alpha \delta_{i}-k$ multiplied by the probability of renting to each type. Aggregating over landlords gives $\mathbb{E}(k)+\sum_{i=L T, S T} e_{i} H\left(1-\alpha \delta_{i}\right)\left[1-\alpha \delta_{i}-\mathbb{E}\left(k \mid k<1-\alpha \delta_{i}\right)\right]$. This aggregate utility slightly differs from the workers'. However, the nexus between HMR and the demand for job protection remains. Consider the two polar cases already presented below Proposition 1. In the absence of HMR, $\alpha=0$, the landlords' objective is simply $\mathbb{E}(k)+e(1-\mathbb{E}(k))$. Therefore, landlords under the veil of ignorance want to maximize employment and their preferred dismissal cost is $t=0$. Alternatively, suppose $\alpha=1$. Then landlords' preferred job protection maximizes $\mathbb{E}(k)+\sum_{i=L T, S T} e_{i} H\left(1-\delta_{i}\right)\left[1-\delta_{i}-\mathbb{E}\left(k \mid k<1-\delta_{i}\right)\right]$. Setting $t=0$ gives $\mathbb{E}(k)$ as the rental market collapses. An increase in $t$ would make $H\left(1-\delta_{L T}\right)>0$, thereby generating positive surplus in the rental market.

Like young workers, landlords support job protection because it increases rental market efficiency. They are willing to decrease employment, the pool of potential renters, to benefit from a technology that reduces uncertainty about applicants to rentals.

\section{2 | Other housing market risks}

Our arguments apply to alternative risks affecting the rental contract or even the mortgage contract. These risks must be correlated with the probability of long-term success in an employment relationship, whereas landlords or lenders face a screening problem taking place after the labor contract choice.

Still on the rental market, consider the risk of damage to the dwelling due to tenant's negligence. Workers who lose their jobs do not necessarily damage the dwelling as a reaction to the job loss. However, the characteristics associated with being successful in a LT employment relationship may be correlated with the characteristics associated with caring for a home. In such a situation, the labor contract conveys a signal on the risk of damage. If the housing regulation increases the loss incurred by the landlord in case of damage, then the value of this signal increases with job protection.

The need for a signaling technology is not specific to the rental market. The market for properties offers a similar situation where the lender must assess the borrower's ability to repay the debt. The costs of litigation vary considerably across countries and frequently amount to significant proportions of property values. The OECD Economic Outlook no. 75, for instance, displays two measures of such costs for a subset of OECD countries. They both consider a particular dispute, the case of a mortgage default. The time required by enforcement procedures varies from 2 to 3 months in Finland to 60-84 months in Italy. The administrative costs of the procedure in percentage of property value vary from $2.5 \%$ in Finland to $18.7 \%$ in Belgium. Mortgage enforcement costs motivate a demand for job protection as a technology signaling the borrower's risk. We do not insist much on this case because youth do not have a large access to the market for properties. 


\section{3 | Wages}

In our framework, job protection is the only technology that can transmit labor market signals to alternative markets. However, the wage may also convey some information on workers' chances of success. For the sake of discussion, suppose that the wage is a nondecreasing function of the individual success probability $P$ and ability $X$ that is nontrivially distributed in the population, that is, $w=w(p, x)$ with $w_{p}(p, x) \geq 0$ and $w_{x}(p, x)>0$. The demand for job protection vanishes when $X$ is perfectly correlated with $P$. Then, the wage perfectly reveals the risk of default and landlords do not need additional information.

There are many reasons why $X$ and $P$ are imperfectly correlated. Suppose for instance that $x$ is a measure of outside options or bargaining ability. These are very weakly related to the idiosyncratic match quality. Moreover, there may be a trade-off between the wage and the job stability. In such cases, landlords are confronted with a complicated signal extraction problem. In practice they cannot simply invert the wage function to deduce the success probability $p$.

Collective bargaining may also imply that the individual probability of success and the wage are imperfectly correlated. A substantial share of wages are affected by collective bargaining. Bargained wages then redistribute income from high- $p$ workers to low- $p$ ones. When collective bargaining is very widespread, wages are weakly informative about individual chances of being successful. Therefore, the demand for EPL as a signaling technology should increase with the extent of collective bargaining.

\subsection{Job protection and the risk of dismissal}

In the basic model, the individual risk of dismissal is not affected by EPL. The average risk of dismissal among LT workers decreases with job protection for pure composition effects as in Cahuc et al. (2016) and Pries and Rogerson (2005). There is another strand of literature based on Mortensen and Pissarides (1994) where employed workers are submitted to idiosyncratic productivity shocks and job protection reduces the individual probability of dismissal. We now account for both types of effects, that is, composition and individual effects.

With probability $1-p$ the firm incurs an operative loss $-\pi$, where $\pi$ is drawn from the cdf $G$ on the support $(0, \infty)$. Workers occupying a ST job are always dismissed in such a case, whereas workers in a LT contract are dismissed when $\pi>t$. The threshold probability $p_{\mathrm{LT}}$ solves $p_{\mathrm{LT}}\left(y_{\mathrm{L}}-w\right)=p_{\mathrm{LT}}\left(y_{\mathrm{H}}-w\right)-\left(1-p_{\mathrm{LT}}\right) d(t)$, where $d(t)=-\int_{0}^{t} \pi d G(\pi)-[1-G(t)] t$. This gives $p_{\mathrm{LT}}=d(t) /(\Delta y+d(t))$. The free-entry condition implies

$$
c=\frac{m\left(\theta^{*}\right)}{\theta^{*}}\left\{\int_{p_{L T}}^{1}(\Delta y+d(t))\left(p-p_{L T}\right) d F(p)+\left(y_{L}-w\right) \mathbb{E}(P)\right\}
$$

whereas ST, LT, and overall employment are $e_{\mathrm{LT}}=m\left(\theta^{*}\right) \operatorname{Pr}\left(P \geq p_{\mathrm{LT}}\right)\left(\mathbb{E}\left(P \mid P \geq p_{\mathrm{LT}}\right)+\left(1-\mathbb{E}\left(P \mid P \geq p_{\mathrm{LT}}\right)\right) G(t)\right)$, $e_{\mathrm{ST}}=\operatorname{Pr}\left(P<p_{\mathrm{LT}}\right) \mathbb{E}\left(P \mid P<p_{\mathrm{LT}}\right)$, and $e=m\left(\theta^{*}\right) \times\left[\mathbb{E}(P)+\operatorname{Pr}\left(P \geq p_{\mathrm{LT}}\right)\left(1-\mathbb{E}\left(P \mid P \geq p_{\mathrm{LT}}\right)\right) G(t)\right]$.

Like the basic model, the cost of dismissal distorts the allocation of ST and LT contracts. Therefore, this cost reduces the supply of vacancies and increases the share of ST contracts. However, now it also reduces the individual job loss probability for workers with a LT contract. Therefore, the overall effect of $t$ on employment is ambiguous.

Landlords make their decision on the basis of the following average default probabilities:

$$
\begin{gathered}
\delta_{\mathrm{LT}}=\left[1-\frac{\int_{p_{\mathrm{LT}}}^{1} p d F(p)}{1-F\left(p_{\mathrm{LT}}\right)}\right] \times[1-G(t)], \\
\delta_{\mathrm{ST}}=1-\frac{\int_{0}^{p_{L T}} p d F(p)}{F\left(p_{\mathrm{LT}}\right)} .
\end{gathered}
$$


The cost of dismissal still induces risk selection into ST and LT employment, which decreases both default probabilities. It further decreases the average LT workers' default probability by reducing the individual risk of dismissal.

The emancipation probability is

$$
q=m\left(\theta^{*}\right)\left[\left(1-F\left(p_{\mathrm{LT}}\right)\right)\left(1-\delta_{\mathrm{LT}}\right) H\left(1-\alpha \delta_{\mathrm{LT}}\right)+F\left(p_{\mathrm{LT}}\right)\left(1-\delta_{\mathrm{ST}}\right) H\left(1-\alpha \delta_{\mathrm{ST}}\right)\right]
$$

When $\alpha=0$, the emancipation probability is $q=e H(1)$. Therefore, the optimal cost of dismissal maximizes employment. When $\alpha=1$, people have two reasons to set job protection above the employment-maximizer parameter. On the one hand, job protection improves screening as in the basic model. The transmission of high-quality signals to landlords improves access to rentals and makes emancipation easier. On the other hand, the cost of dismissal reduces the individual default risk of workers in LT contracts. This further increases their chance of obtaining a rental. This latter effect is similar to Decreuse and van Ypersele (2011) who study the impact of job protection on mortgage prices.

\section{5 | HMR, employment, and workers' mobility}

In the basic model, the only effect of HMR on employment is due to the correlated demand for job protection. We now follow Rupert and Wasmer (2012) and introduce a direct effect of HMR on employment due to its negative impact on worker mobility. Accounting for this effect modifies the reasoning because, now, facilitating access to rentals can also increase employment. We show that EPL is still needed as a firm discipline device to make firms more selective and improve access to rentals.

To consider an extreme case, suppose that occupying a job requires moving from the family home to an alternative location. Therefore, employment and emancipation coincide. Once a worker is met, the firm chooses the contract type accounting for the chance of having a rental. Offering a ST contract gives $p\left(y_{L}-w\right) H\left(1-\alpha \delta_{S T}\right)$, whereas offering a LT contract gives $p\left(y_{H}-w\right) H\left(1-\alpha \delta_{L T}\right)-(1-p) t$.

The free-entry condition implies

$$
c=\frac{m(\theta)}{\theta}\left\{\int_{0}^{p_{L T}} H\left(1-\alpha \delta_{S T}\right) p\left(y_{L}-w\right) d F(p)+\int_{p_{L T}}^{1}\left[H\left(1-\alpha \delta_{L T}\right) p\left(y_{H}-w\right)-t(1-p)\right] d F(p)\right\}
$$

and the threshold probability is

$$
p_{\mathrm{LT}}=\frac{t}{\left(y_{H}-w\right) H\left(1-\alpha \delta_{\mathrm{LT}}\right)-\left(y_{\mathrm{L}}-w\right) H\left(1-\alpha \delta_{S T}\right)+t} .
$$

Firms take as given the group-specific mean default probability used by landlords to decide whether to accept a potential tenant or not. However, such default probabilities depend on firms' policies to offer ST and LT contracts.

To ease notations, we suppose that $P$ follows the uniform law on $[0,1]$. In equilibrium the selection threshold solves the following fixed-point problem:

$$
p_{\mathrm{LT}}=\frac{t}{\left(y_{H}-w\right) H\left(1-\alpha / 2+\alpha p_{\mathrm{LT}} / 2\right)-\left(y_{\mathrm{L}}-w\right) H\left(1-\alpha+\alpha p_{\mathrm{LT}} / 2\right)+t} .
$$

When $\alpha=0$, the probability of having a rental is equal to one for both groups of workers. Thus, $p_{\mathrm{LT}}=t /(\Delta y+t)$ as in the basic model. When $\alpha>0$, the right-hand side of Equation (19) is affected by $p_{\mathrm{LT}}$ in two opposite ways. Both mean default probabilities decrease with $p_{\mathrm{LT}}$, which implies that both ST and LT workers are more likely to find a rental. The negative impact of $p_{\mathrm{LT}}$ on $\delta_{\mathrm{LT}}$ is a stabilizer effect: an increase in $p_{\mathrm{LT}}$ raises LT workers' probability of obtaining a rental, which provides firms with incentive to offer LT contracts. Conversely, the negative impact of $p_{\mathrm{LT}}$ on $\delta_{S T}$ is a multiplier effect: increasing $p_{\mathrm{LT}}$ reduces firms' incentive to offer LT contracts. 
There may be multiple equilibria. The magnitudes of the stabilizer and multiplier effects depend on the density $H^{\prime}$ of the opportunity cost distribution. Thus, it is possible that the multiplier effect dominates the stabilizer one. Multiple equilibria can be ranked by values of $p_{\mathrm{LT}}$. High- $p_{\mathrm{LT}}$ equilibria correspond to situations where firms strongly select workers into LT contracts. We refer to these equilibria as high-selection equilibria. Conversely, in low-selection equilibria $p_{\mathrm{LT}}$ is small and the access to rental contracts is relatively easy.

In high-selection equilibria, few workers are hired in LT contracts and easily find rentals, whereas the large pool of workers hired in ST contracts benefit from a moderate access to rentals. In low-selection equilibria, many workers are hired in LT contracts and face more difficulties in finding dwellings than in high-selection equilibria. Moreover, the smaller number of workers hired in ST contracts struggle to find rentals.

In equilibrium, firms under-select workers in LT jobs because they do not take into account the impacts of their hiring decisions on the signals received by landlords. To see this, consider the case where such signals are actually accounted for by firms when they maximize their expected profits. We obtain

$$
\begin{aligned}
p_{\mathrm{LT}}= & \frac{t}{\left(y_{\mathrm{H}}-w\right) H\left(1-\alpha / 2+\alpha p_{\mathrm{LT}} / 2\right)-\left(y_{\mathrm{L}}-w\right) H\left(1-\alpha+\alpha p_{\mathrm{LT}} / 2\right)+t} \\
& -\alpha \frac{\frac{d \delta S T}{d p_{\mathrm{LT}}} h\left(1-\alpha \delta_{\mathrm{ST}}\right) \int_{0}^{p_{\mathrm{LT}}} P\left(y_{\mathrm{L}}-w\right) d P+\frac{d \delta \mathrm{LT}}{d p_{\mathrm{LT}}} \int_{p_{\mathrm{LT}}}^{1} h\left(1-\alpha \delta_{\mathrm{LT}}\right) P\left(y_{\mathrm{H}}-w\right) d P}{\left(y_{\mathrm{H}}-w\right) H\left(1-\alpha / 2+\alpha p_{\mathrm{LT}} / 2\right)-\left(y_{\mathrm{L}}-w\right) H\left(1-\alpha+\alpha p_{\mathrm{LT}} / 2\right)+t} \\
> & \frac{t}{\left(y_{\mathrm{H}}-w\right) H\left(1-\alpha / 2+\alpha p_{\mathrm{LT}} / 2\right)-\left(y_{\mathrm{L}}-w\right) H\left(1-\alpha+\alpha p_{\mathrm{LT}} / 2\right)+t},
\end{aligned}
$$

because $d \delta_{i} / d p_{\mathrm{LT}}<0$ for $i=\mathrm{ST}$, LT.

The resulting threshold is larger than in equilibrium where firms ignore the signal conveyed by hiring decisions. The first line of the right-hand side corresponds to the hiring threshold that firms set in the decentralized allocation. The second line accounts for the signal transmitted to landlords. Given $p_{\mathrm{LT}}$ decreases both group-specific rent default probabilities - that is, $d \delta_{\mathrm{ST}} / d p_{\mathrm{LT}}<0$ and $d \delta_{\mathrm{LT}} / d p_{\mathrm{LT}}<0-$ the term on the second line is negative and $p_{\mathrm{LT}}$ is larger than in the decentralized allocation. The situation is typical of the prisoner's dilemma. It is in the collective interest of firms to restrict the supply of LT contracts so as to transmit high-quality signals to landlords. At private level, each firm has an incentive to deviate from this strategy to increase the probability that the worker will find a rental and the job will be occupied. In equilibrium firms offer too many LT contracts and landlords are insufficiently willing to rent their dwellings.

Like the basic model, HMR promotes job protection because firms are insufficiently selective. We now illustrate this statement by confronting two polar cases. In both of them, the optimal cost of dismissal maximizes the emancipation probability, which is here equivalent to maximizing employment. When $\alpha=0$, landlords accept all potential tenants and the cost of dismissal reduces employment. Therefore, the optimal cost is $t^{*}=0$. Conversely, when $\alpha=1$, having $t=0$ implies that $p_{\mathrm{LT}}=0$. Firms do not select workers and the mean default probabilities are $\delta_{\mathrm{LT}}=1 / 2$ and $\delta_{\mathrm{ST}}=1$. Thus, $\mu_{\mathrm{LT}}=\mu_{\mathrm{ST}}=0$ and employment and emancipation are equal to 0 . It follows that the optimal cost of dismissal is $t^{*}>0$.

In this extended model, employment and emancipation coincide. Therefore, optimal job protection actually maximizes employment. In the more general case where only a share of job offers require moving to an alternative location, there is still a trade-off between employment and access to rentals as in the basic model.

\subsection{Insider-outsider theory of job protection}

The insider-outsider theory of labor market institutions as described by Saint-Paul (2001) posits that existing institutions maximize the well-being of the majority of workers installed in LT jobs. In the basic model, we study the preferences of a typical individual under the veil of ignorance. However, the ex-ante risks of losing future jobs and defaulting on future rents may differ in the youth population. We now consider the preferences of heterogenous 
individuals in terms of such risks. We suppose that the random variable $P$ describes a worker-specific characteristic instead of a match-specific one. Accordingly, we now refer to $P$ as the worker type. This leads us to distinguish two groups of persons who prefer strongly protected jobs: individuals with particularly high and particularly low risks of being dismissed.

Hereafter, we present the results in terms of preferred threshold $p_{\mathrm{LT}}$. This is equivalent to analyze preferences vis-à-vis $t$, having in mind that $t=\Delta y \times p_{\mathrm{LT}} /\left(1-p_{\mathrm{LT}}\right)$. We denote by $p_{\mathrm{LT}}^{*}(p)$ the threshold that maximizes the expected utility of a type- $p$ worker.

The expected utility $U\left(p, p_{\mathrm{LT}}\right)$ of a type- $p$ worker is

$$
U\left(p, p_{\mathrm{LT}}\right)=\left\{\begin{array}{ll}
u_{\mathrm{ST}}\left(p, p_{\mathrm{LT}}\right) & \text { if } p \leq p_{\mathrm{LT}} \\
u_{\mathrm{LT}}\left(p, p_{\mathrm{LT}}\right) & \text { if } p>p_{\mathrm{LT}}
\end{array},\right.
$$

where $u_{i}\left(p, p_{\mathrm{LT}}\right)=p m\left(\theta^{*}\right) H\left(1-\alpha \delta_{i}\right)(w-1)$ is the expected payoff of workers in contracts of type $i=\mathrm{LT}$, ST, that is, the probability of success, $p$, times the probability of getting a job, $m\left(\theta^{*}\right)$, multiplied by the probability of getting a rental, $H\left(1-\alpha \delta_{i}\right)$, and by the wage net of the rent, $w-1$.

We assume the functions $u_{S T}$ and $u_{\mathrm{LT}}$ are single-peaked with respect to $p_{\mathrm{LT}}$, taking their maximum in $p_{\mathrm{ST}}^{+}$ and $p_{\mathrm{LT}}^{+}$, respectively. In Appendix $\mathrm{C}$, we provide an example where this is indeed the case. The corresponding costs of dismissal are $t_{\mathrm{ST}}^{+}=\Delta y p_{\mathrm{ST}}^{+} /\left(1-p_{\mathrm{ST}}^{+}\right)$and $t_{\mathrm{LT}}^{+}=\Delta y \times p_{\mathrm{LT}}^{+} /\left(1-p_{\mathrm{LT}}^{+}\right)$. Note that $t_{\mathrm{LT}}^{+}$is not necessarily larger than $t_{S T}^{+}$.

When $\alpha=0$, having a LT contract does not improve the probability of finding a rental. Therefore, the function $U$ is continuous with respect to $p$ in $p=p_{\mathrm{LT}}$. When $\alpha>0$, we have $\delta_{\mathrm{LT}}<\delta_{\mathrm{ST}}$. Therefore, all workers prefer LT contracts to benefit from better access to rentals. Consequently, the function $U$ jumps upward when $p$ crosses the threshold $p_{\mathrm{LT}}$. Figure 3 depicts $U$ as a function of $p_{\mathrm{LT}}$ for a type- $p$ worker when $\alpha>0$. When $p_{\mathrm{LT}}<p$, the worker is hired in a LT contract and enjoys $u_{\mathrm{LT}}$. When $p_{\mathrm{LT}}>p$, the worker is hired in a ST contract and obtains $u_{\mathrm{ST}}$. Therefore, the normalized expected utility function initially describes the $u_{\mathrm{LT}}$ curve, jumps downward when $p_{\mathrm{LT}}$ crosses $p$, and follows the $u_{\mathrm{ST}}$ curve afterwards. Let $\bar{p}$ be the worker's type such that the person is indifferent between $\bar{p}$ and $p_{\mathrm{ST}}^{+}$. When $\alpha=0, \bar{p}=p_{\mathrm{ST}}^{+}$by construction. When $\alpha>0$, we have $H\left(1-\alpha \delta_{\mathrm{LT}}\right)>H\left(1-\alpha \delta_{\mathrm{ST}}\right)$ and the limit type is such that $\bar{p}<\min \left\{p_{\mathrm{LT}}^{+}, p_{\mathrm{ST}}^{+}\right\}$. In Figure 3, we have $\bar{p}<p_{\mathrm{ST}}^{+}<p_{\mathrm{LT}}^{+}$.

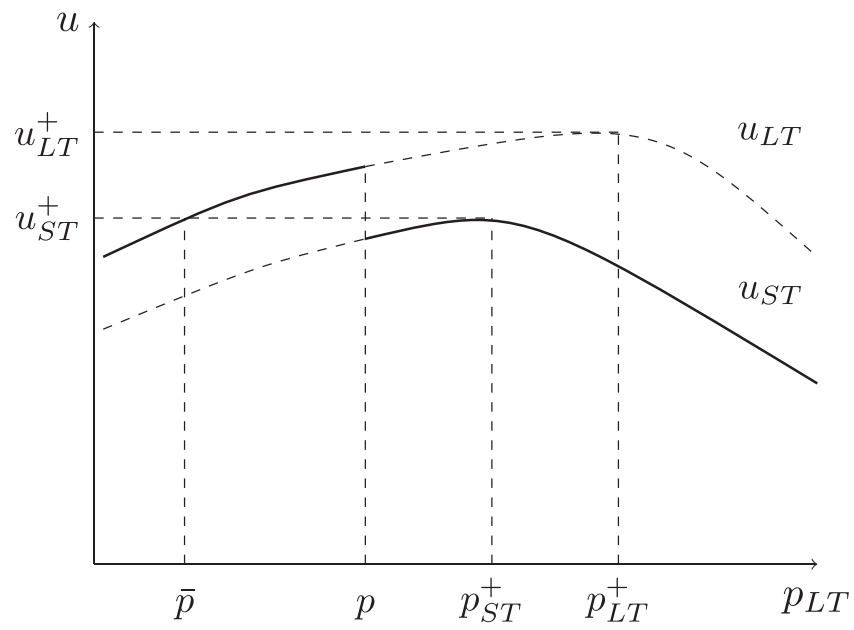

FIGURE 3 Preferred job protection when workers know their type. The bold line shows the expected utility of a type- $p$ worker as a function of $p_{\mathrm{LT}}$. It goes from $u_{\mathrm{LT}}$ to $u_{\mathrm{ST}}$ when $p_{\mathrm{LT}}$ crosses $p$. The payoff functions $u_{\mathrm{ST}}$ and $u_{\mathrm{LT}}$, utility maximizers $p_{S T}^{+}$and $p_{L T}^{+}$, and the limit type $\bar{p}$ are defined in the text 
The reasoning features three groups of individuals with heterogenous support for job protection. The preferred threshold is such that

$$
p_{\mathrm{LT}}^{*}(p)= \begin{cases}p_{\mathrm{LT}}^{+} & \text {if } p \geq p_{\mathrm{LT}}^{+} \\ p & \text { if } p<p<p_{\mathrm{LT}}^{+} . \\ p_{S T}^{+} & \text {if } p \leq p\end{cases}
$$

Large- $p$ individuals, that is, $p \geq p_{\mathrm{LT}}^{+}$, prefer $p_{\mathrm{LT}}^{+}$, the level of job protection maximizing the utility associated to LT contracts. Such individuals are sure to become LT workers and incline to high selection into this group, thereby ensuring that landlords are willing to offer them a rental. The level of protection is only limited by its negative impact on job openings.

Low- $p$ individuals, that is, $p \leq \bar{p}$, prefer $p_{S T}^{+}$, the level of job protection maximizing the utility associated to ST contracts. This level can be substantially large for reasons symmetric to large- $p$ individuals. Low- $p$ individuals are sure to become ST workers. Therefore, they want to be mixed with a pool of high types, which is the case when LT jobs are very selective.

Lastly, medium- $p$ individuals, that is, $\bar{p}<p<p_{\mathrm{LT}}^{+}$, want to become LT workers. Therefore, they prefer the largest cost of dismissal that is compatible with their selection into the pool of LT workers, which implies $p_{\mathrm{LT}}^{*}(p)=p$.

Job protection is supported by a coalition formed of low-skilled (low $p$ ) and high-skilled workers (large $p$ ). Both groups want LT jobs to be very selective so that the mean default probabilities associated with their group are high. The intermediate group of workers is less attached to job protection and less homogenous. Each worker of this group wants a LT contract, but also wants to exclude lower $p$ individuals from LT jobs.

\section{5 | CONCLUSION}

In many European countries, young workers are over exposed to unemployment and job instability and quit the family home remarkably late. Meanwhile, long-term jobs are strongly protected and the rental market is heavily regulated. Even though this situation calls for reforms of labor contracts, young workers are not willing to reduce protection of long-term jobs they do not hold. This paper provides a rationale to the lack of youth support for reforms of job protection. When the rental market is heavily regulated, protecting long-term contracts provides a screening technology improving access to the housing market. The risks of rent default and job dismissal are inherent in individuals and positively correlated. Employers who offer a long-term contract transmit a signal to landlords about the worker's type. The quality of this signal increases with the strictness of job protection.

Our arguments apply to alternative risks and markets. These risks must be correlated with the probability of long-term success in a contractual relationship, whereas agents on the other side of the market face a screening problem taking place after the labor contract choice. For instance, they may also be applied to the marriage market. There, job protection may be particularly useful to screen potential life partners. The divorce regulation increases the cost of divorce by reducing the utility obtained by each divorcee. Thus, marriage candidates must assess the risk of divorce before accepting marriage proposals. On the speculative ground that long-term success in an employment relationship is correlated with long-term success in a partnership, the labor contract conveys a signal on one's ability to maintain a solid marriage. Once adapted to the marriage market, our work predicts that the extent of divorce regulation promotes the social demand for job protection.

Our paper calls for reforms of the housing market. Ideally, one would like to reduce the level of procedural formalism in case of disputes between landlords and tenants. However, it is hardly feasible to modify it independently from the rest of the judicial system. Therefore, the most important reform consists of insuring 
landlords against rent default. A key benefit of such an insurance consists in weakening the political support for job protection, thereby opening the door to labor market reforms. In France, the recent launch of the Visale guarantee is a step in this direction. This guarantee against rent default is accessible to all individuals under 30 who are not in education ${ }^{6}$ and individuals above 30 in short-term employment. It covers all rents until the end of the rental contract. Eligibility conditions are fairly weak: the rent cannot exceed 1,500 euros per month in Paris and 1,300 euros elsewhere and the rent-to-income ratio cannot exceed $50 \%$. Visale is financed by Action-Logement, an institutional body related to the State. Therefore, it is free for renters and landlords.

\section{ACKNOWLEDGMENTS}

This paper benefited from the comments of participants to the SaM conference in Amsterdam and the AMSE-Banque de France labor market conference in Aix-en-Provence. We thank Bruno van der Linden, a referee and an associate editor of this review for their careful reading and suggestions. We also thank the Conseil Régional Provence Alpes Côte d'Azur and the Chaire Transitions Démographiques, Transitions Economiques for financial support.

\section{REFERENCES}

Alesina, A., Algan, Y., Cahuc, P., \& Giuliano, P. (2015). Family values and the regulation of labor. Journal of the European Economic Association, 13, 599-630.

Algan, Y., \& Cahuc, P. (2006). Job protection: The macho hypothesis. Oxford Review of Economic Policy, 22, $390-410$.

Algan, Y., \& Cahuc, P. (2009). Civic virtue and labor market institutions. American Economic Journal: Macroeconomics, 1 , 111-145.

Balas, A., LaPorta, R., Lopez-de-Silanes, F., \& Shleifer, A. (2009). The divergence of legal procedures. American Economic Journal: Economic Policy, 1, 138-162.

Blanchard, O., \& Tirole, J. (2008). The joint design of unemployment compensation and employment protection: A first pass. Journal of the European Economic Association, 6, 45-77.

Bonleu, A. (Forthcoming). Procedural formalism and social networks in the housing market. Annals of Economics and Statistics.

Booth, A. L., Francesconi, M., \& Frank, J. (2002). Temporary jobs: Stepping stones or dead ends? Economic Journal, 112, 189-213.

Botero, J., Djankov, S., LaPorta, R., \& Lopez-De-Silanes, F. (2004). The regulation of labor. Quarterly Journal of Economics, 119, 1339-1382.

Cahuc, P., Charlot, O., \& Malherbet, F. (2016). Explaining the spread of temporary jobs and its impact on labor turnover. International Economic Review, 57, 533-572.

Casas-Arce, P., \& Saiz, A. (2010). Owning versus renting: Do courts matter? Journal of Law and Economics, 53, 137-165.

Decreuse, B., \& vanYpersele, T. (2011). Housing market regulation and the social demand for job protection. Journal of Public Economics, 95, 1397-1409.

De Donder, Ph., \& Pestieau, P. (2017). Private, social, and self-insurance for long-term care in the presence of family help. Journal of Public Economic Theory, 19, 18-37.

Deng, Y., Quigley, J. M., VanOrder, R., \& Mac, F. (1996). Mortgage default and low downpayment loans: The costs of public subsidy. Regional Science Urban Economics, 26, 263-285.

Djankov, S., LaPorta, R., Lopez-De-Silanes, F., \& Shleifer, F. (2003). Courts. Quarterly Journal of Economics, 118, $453-517$.

Eichholtz, P. M. A. (1995). Regional economic stability and mortgage default risk in the Netherlands. Real Estate Economics, 23, 421-439.

Gerardi, K., Herkenhoff, K. F., Ohanian, L. E., \& Willen, P. S. ( 2015). Canat pay or wonat pay? Unemployment, negative equity, and strategic default. NBER Working Paper 21630.

Leonardi, M., \& Pica, G. (2013). Who pays for it? The heterogeneous wage effects of employment protection legislation. Economic Journal, 123, 1236-1278.

Mortensen, D. T., \& Pissarides, C. A. (1994). Job creation and job destruction in the theory of unemployment. Review of Economic Studies, 61, 397-415.

\footnotetext{
${ }^{6}$ Students who do not depend on parents' income and scholarship holders are also eligible.
} 
Nivière, D. (2006). Les ménages ayant des difficultés à payer leur loyer. Etudes et Résultats, 534.

OECD (2004). OECD Economic Outlook no. 75.

Postlewaite, A., Samuelson, L., \& Silverman, D. (2008). Consumption commitments and employment contracts. Review of Economic Studies, 75, 559-578.

Pries, M., \& Rogerson, R. (2005). Hiring policies, labor market institutions, and labor market flows. Journal of Political Economy, 113, 811-839.

Rupert, P., \& Wasmer, E. (2012). Housing and the labour market: Time to move and aggregate unemployment. Journal of Monetary Economics, 59, 24-36.

Saint-Paul, G. (2001). Political economy of the labour market. Oxford, UK: Oxford University Press.

Serrano-Diaz, L. (2005). Income volatility and residential mortgage delinquency across the EU. Journal of Housing Economics, 14, 153-177.

Stupnytska, Y., \& Zaharieva, A. (2017). Optimal policy and the role of social contacts in a search model with heterogeneous workers. Journal of Public Economic Theory, 19, 957-985.

How to cite this article: Bonleu A, Decreuse B, van Ypersele T. Job protection, housing market regulation, and the youth. Journal of Public Economic Theory. 2018;1-20. https://doi.org/10.1111/jpet.12323

\section{APPENDIX A: PROOF OF PROPOSITION 1}

(i) Proved in the text below Proposition 1.

(ii) Emancipation is $q(t, \alpha)=e(t) \bar{\mu}(t, \alpha)$. Note first that $q(0, \alpha)=e(0) \bar{\mu}(0, \alpha)>\lim _{t \rightarrow \infty} e(t) \bar{\mu}(t, \alpha)$ because $\lim _{t \rightarrow \infty} \bar{\mu}(t, \alpha)=\bar{\mu}(0, \alpha)=H\left[1-\alpha\left(1-\mathbb{E}_{(}(P)\right)\right]$ and $e$ strictly decreases with $t$. It follows that $t^{*}(\alpha)<<\infty$. Moreover $q_{t}(0, \alpha)=e^{\prime}(0) \bar{\mu}(0, \alpha)+e(0) \bar{\mu}_{t}(0, \alpha)$. As $\bar{\mu}(0,1)=0$, we have $q_{t}(0,1)=e(0) \bar{\mu}_{t}(0,1)$. But

$$
\begin{aligned}
\mathbb{E}_{(}(P) \bar{\mu}_{t}(t, \alpha)= & -f\left(p_{\mathrm{LT}}\right)\left(d p_{\mathrm{LT}} / d t\right)\left(1-\delta_{\mathrm{LT}}\right) H\left(1-\alpha \delta_{\mathrm{LT}}\right)-\left(1-F\left(p_{\mathrm{LT}}\right)\right)\left(d \delta_{\mathrm{LT}} / d t\right) H\left(1-\alpha \delta_{\mathrm{LT}}\right) \\
& -\alpha\left(d \delta_{\mathrm{LT}} / d t\right)\left(1-F\left(p_{\mathrm{LT}}\right)\right)\left(1-\delta_{\mathrm{LT}}\right) h\left(1-\alpha \delta_{\mathrm{LT}}\right) .
\end{aligned}
$$

Thus,

$$
\begin{aligned}
\mathbb{E}(P) \bar{\mu}_{t}(0,1)= & -f(0)\left(d p_{\mathrm{LT}} / d t\right)\left(1-\delta_{\mathrm{LT}}\right) H(\mathbb{E}(P))-\left(1-F\left(p_{\mathrm{LT}}\right)\right)\left(d \delta_{\mathrm{LT}} / d t\right) H(\mathbb{E}(P)) \\
& -\alpha\left(d \delta_{\mathrm{LT}} / d t\right)\left(1-F\left(p_{\mathrm{LT}}\right)\right)\left(1-\delta_{\mathrm{LT}}\right) h(\mathbb{E}(P)) \\
= & -\alpha\left(d \delta_{\mathrm{LT}} / d t\right)\left(1-F\left(p_{\mathrm{LT}}\right)\right)\left(1-\delta_{\mathrm{LT}}\right) h(\mathbb{E}(P))>0 .
\end{aligned}
$$

Therefore, $q_{t}(0,1)>0$. It follows that $t^{*}(1) \in(0, \infty)$ and solves $q_{t}\left(t^{*}(1), 1\right)=0$. By continuity of function $\mu_{t}$ with respect to $\alpha$, the result remains true in a neighborhood of $\alpha=1$. Therefore, there is $\tilde{\alpha} \in(0,1)$ such that $t^{*}(\alpha)>0$ and solves $q_{t}\left(t^{*}(\alpha), 1\right)=0$ for all $\alpha \geq \tilde{\alpha}$.

(iii) When $t^{*}(\alpha)$ is differentiable,

$$
\frac{d t^{*}(\alpha)}{d \alpha}=-\frac{d\left(\frac{e^{\prime}\left(t^{*}\right)}{e\left(t^{*}\right)}+\frac{\bar{\mu}_{t}\left(t^{*}, \alpha\right)}{\bar{\mu}\left(t^{*}, \alpha\right)}\right) / d \alpha}{d\left(\frac{e^{\prime}\left(t^{*}\right)}{e\left(t^{*}\right)}+\frac{\bar{\mu}_{t}\left(t^{*}, \alpha\right)}{\bar{\mu}\left(t^{*}, \alpha\right)}\right) / d t} .
$$

The denominator is negative because $t^{*}(\alpha)$ is an interior maximum, which means that

$$
\operatorname{sign} \frac{d t^{*}(\alpha)}{d \alpha}=\operatorname{sign} \frac{d\left(\frac{e^{\prime}\left(t^{*}\right)}{e\left(t^{*}\right)}+\frac{\bar{\mu}_{t}\left(t^{*}, \alpha\right)}{\bar{\mu}\left(t^{*}, \alpha\right)}\right)}{d \alpha} .
$$


But

$$
\frac{d\left(\frac{e^{\prime}\left(t^{*}\right)}{e\left(t^{*}\right)}+\frac{\bar{\mu}_{t}\left(t^{*}, \alpha\right)}{\bar{\mu}\left(t^{*}, \alpha\right)}\right)}{d \alpha}=\frac{\bar{\mu}_{t \alpha}\left(t^{*}, \alpha\right)}{\bar{\mu}\left(t^{*}, \alpha\right)}-\frac{\bar{\mu}_{t}\left(t^{*}, \alpha\right) \bar{\mu}_{\alpha}\left(t^{*}, \alpha\right)}{\bar{\mu}\left(t^{*}, \alpha\right)^{2}} .
$$

The second term is positive. Indeed, $\bar{\mu}_{t}\left(t^{*}, \alpha\right)>0$ because $\frac{\bar{\mu}_{t}\left(t^{*}, \alpha\right)}{\bar{\mu}\left(t^{*}, \alpha\right)}=-\frac{e^{\prime}\left(t^{*}\right)}{e\left(t^{*}\right)}>0$. Moreover,

$$
\mathbb{E}(P) \bar{\mu}_{\alpha}\left(t^{*}, \alpha\right)=-\delta_{\mathrm{LT}} h\left(1-\alpha \delta_{\mathrm{LT}}\right) \int_{p_{\mathrm{LT}}}^{1} p f(p) d p-\delta_{\mathrm{ST}} h\left(1-\alpha \delta_{\mathrm{ST}}\right) \int_{0}^{p_{\mathrm{LT}}} p f(p) d p<0
$$

As for the first term, we have

$$
\begin{aligned}
\mathbb{E}(P) \bar{\mu}_{t \alpha}\left(t^{*}, \alpha\right)= & f\left(p_{\mathrm{LT}}\right) \frac{d p_{\mathrm{LT}}}{d t}\left\{\left(p_{\mathrm{LT}}+1-\delta_{\mathrm{LT}}\right)\left(1-\delta_{\mathrm{LT}}\right)\left[h\left(1-\alpha \delta_{\mathrm{LT}}\right)-\alpha \delta_{\mathrm{LT}} h^{\prime}\left(1-\alpha \delta_{\mathrm{LT}}\right)\right]\right. \\
& \left.+\left(\delta_{\mathrm{ST}}+p_{\mathrm{LT}}-1\right)\left(1-\delta_{\mathrm{ST}}\right)\left[h\left(1-\alpha \delta_{\mathrm{ST}}\right)-\alpha \delta_{\mathrm{ST}} h^{\prime}\left(1-\alpha \delta_{\mathrm{ST}}\right)\right]+p_{\mathrm{LT}}\left(\delta_{\mathrm{LT}} h\left(1-\alpha \delta_{\mathrm{LT}}\right)-\delta_{\mathrm{ST}} h\left(1-\alpha \delta_{\mathrm{ST}}\right)\right)\right\} .
\end{aligned}
$$

When $H$ is uniform, the density $h$ is constant and $h^{\prime}()=$.0 . Therefore,

$$
\mathbb{E}(P) \bar{\mu}_{t \alpha}\left(t^{*}, \alpha\right)=f\left(p_{\mathrm{LT}}\right) \frac{d p_{\mathrm{LT}}}{d t} h\left[\left(1-\delta_{\mathrm{LT}}\right)^{2}-\left(1-\delta_{\mathrm{ST}}\right)^{2}+2 p_{\mathrm{LT}}\left(1-\delta_{\mathrm{ST}}\right)\right]>0
$$

It follows that $t^{*^{\prime}}(\alpha)>0$.

\section{APPENDIX B: ENDOGENOUS RENT}

In the basic model, the rent is exogenous. Having a more protected contract may allow one to pay a lower rent, on top of having a larger probability of obtaining the rental. Our results stay unaffected provided that the return to job protection in terms of a lower rent does not decrease with the extent of housing market regulation. Though this assumption seems plausible, we now provide a model of rent setting where this return is actually independent from HMR.

We suppose that the rent is determined by Nash bargaining between the tenant and the landlord before the job quality is revealed. Whether workers know $P$ at this stage or not is inconsequential because there is no credible way to communicate it to the landlord. Therefore, the landlord and the renter bargain over the rent conditional on the labor contract, that is, the only signal observed by the landlord. The rent $r$ results from

$$
\max _{r \geq 0}\left[\mathbb{E}\left(P(w-r) \mid P \geq p_{\mathrm{LT}}\right)\right]^{\gamma}\left[\mathbb{E}\left(P r \mid P \geq p_{\mathrm{LT}}\right)-k\right]^{1-\gamma}
$$

which is equivalent to

$$
\max _{r \geq 0} \gamma \ln (w-r)+(1-\gamma) \ln \left[r-k / \mathbb{E}\left(P \mid P \geq p_{\mathrm{LT}}\right)\right]
$$

Therefore,

$$
r=(1-\gamma) w+\gamma k / \mathbb{E}\left(P \mid P \geq p_{\mathrm{LT}}\right)
$$


The rent decreases with $p_{\mathrm{LT}}$ : the landlord's outside option is relatively less valued when the probability of receiving the rent increases.

The optimal cost of dismissal must take into account its negative impact on the rent, that is,

$$
t^{*} \in \arg \max _{t \geq 0}\left\{q(w-r)=e(t) \bar{\mu}(t, \alpha) \gamma\left[w-k / \mathbb{E}\left(P \mid P \geq p_{\mathrm{LT}}\right)\right]\right\}
$$

In an interior solution, we have

$$
\frac{e^{\prime}(t)}{e(t)}+\frac{\bar{\mu}_{t}(t, \alpha)}{\bar{\mu}(t, \alpha)}+k \frac{\left[d \mathbb{E}\left(P \mid P \geq p_{\mathrm{LT}}\right) / d t\right] / \mathbb{E}\left(P \mid P \geq p_{\mathrm{LT}}\right)^{2}}{w-k / \mathbb{E}\left(P \mid P \geq p_{\mathrm{LT}}\right)}=0 .
$$

The last term features the return on paying a lower rent. It does not depend on $\alpha$. Therefore, the main result is unchanged: increasing $\alpha$ improves access to the rental market. This pushes optimal job protection further beyond the point that maximizes employment.

\section{APPENDIX C: A CONDITION FOR THE SINGLE-PEAKEDNESS OF PREFERENCES VIS-À-VIS $p_{L T}$}

In the last extension discussed in Section 4, we study workers' demand for job protection when they know their type. To simplify the analysis, we suppose that the expected payoffs $u_{\mathrm{LT}}$ and $u_{\mathrm{ST}}$ are single-peaked vis-à-vis $p_{\mathrm{LT}}$. In this appendix, we provide sufficient conditions ensuring that this is so.

Here are the conditions:

(i) $h^{\prime}(x) \leq 0$ for all $x \in[\mathbb{E}(P), 1]$ and (ii) $m^{\prime \prime}(\theta)+2 m^{\prime}(\theta)^{2}-\frac{m^{\prime}(\theta) m(\theta)^{2} m^{\prime \prime}(\theta) \theta}{m^{\prime}(\theta) \theta-m(\theta)}<0$ for all $\theta \geq 0$. Single-peakedness is guaranteed when the function $u_{i}, i=L T, S T$, is strictly concave:

$$
\frac{d^{2} u_{i}}{d p_{\mathrm{LT}}^{2}}<0 \text { for all } p_{\mathrm{LT}} \in[0,1]
$$

But

$$
\frac{d^{2} u_{i}}{d p_{L T}^{2}}=H\left(1-\alpha \delta_{i}\right)\left[m^{\prime \prime}\left(\frac{d \theta}{d p_{L T}}\right)^{2}+m^{\prime} \frac{d^{2} \theta}{d p_{L T}^{2}}\right]+\alpha m^{\prime}(\theta) h\left(1-\alpha \delta_{i}\right) \frac{d \theta}{d p_{L T}}+m \frac{\alpha^{2}}{4} h^{\prime}\left(1-\alpha \delta_{i}\right) .
$$

As $d \theta / d p_{\mathrm{LT}}<0$, condition (i) implies that the sum of the last two terms is negative. From the free-entry condition (7), we have

$$
\frac{d \theta}{d p_{\mathrm{LT}}}=\frac{\Delta y}{2 c} \frac{m^{2}}{m^{\prime} \theta-m}<0 \quad \text { and } \quad \frac{d^{2} \theta}{d p_{\mathrm{LT}}^{2}}=\left(\frac{d \theta}{d p_{\mathrm{LT}}}\right)^{2} \frac{2 m^{\prime}\left(m^{\prime} \theta-m\right)-m^{2} m^{\prime \prime} \theta}{m^{\prime} \theta-m}
$$

Using this result, the first term of (C1) can be rewritten as

$$
\left[m^{\prime \prime}\left(\frac{d \theta}{d p_{\mathrm{LT}}}\right)^{2}+m^{\prime} \frac{d^{2} \theta}{d p_{\mathrm{LT}}^{2}}\right]=\left(\frac{d \theta}{d p_{\mathrm{LT}}}\right)^{2}\left[m^{\prime \prime}+2 m^{\prime 2}-\frac{m^{\prime} m^{2} m^{\prime \prime} \theta}{m^{\prime} \theta-m}\right]
$$

Therefore, condition (ii) implies single-peakedness. 
Condition (ii) may be satisfied for several matching functions. We now show that it is verified when $m(\theta)=\theta /(1+\theta)$ and $\left(y_{L}-w\right) / c>\sqrt{5}+1$. The function $m$ satisfies the different restrictions given in Section 2. Moreover, the free-entry condition gives

$$
\theta^{*}=\frac{y_{H}-w-p_{L} \Delta y}{2 c}-1
$$

Mutatis mutandis, we have

$$
m^{\prime \prime}+2 m^{\prime 2}-\frac{m^{\prime} m^{2} m^{\prime \prime} \theta}{m^{\prime} \theta-m}=2 \frac{1-\theta-\theta^{2}}{\theta(1+\theta)^{4}}
$$

which is negative when $\theta>(\sqrt{5}-1) / 2$. As $\theta^{*}>\frac{y_{L}-w}{2 c}-1$, this condition is ensured when $\left(y_{L}-w\right) / c>\sqrt{5}+1$. 